\title{
APLICAÇÃO DA TEORIA DAS OPÇÕES REAIS PARA AVALIAÇÃO DE POLÍTICA PÚBLICA: A POLÍTICA INOVAR-AUTO NO SETOR AUTOMOTIVO BRASILEIRO
}

\section{APLICATION REAL OPTIONS THEORY FOR EVALUATING POLICY PUBLIC: THE INOVAR AUTO POLCY IN BRASILIAN AUTOMOTIVE SECTOR}

\author{
Francisco Alexandre de Oliveira* E-mail: faoliveirabr@yahoo.com \\ *Universidade Estadual Paulista (UNESP), São Paulo, SP
}

\begin{abstract}
Resumo: A indústria automobilística tem uma importância crescente no contexto econômico brasileiro. O setor movimenta uma cadeia enorme que engloba fabricantes e fornecedores, postos de gasolina, seguradoras, oficinas mecânicas, borracharias, empresas de comunicação, agências de publicidade, entre outros. Consciente desta importância, o governo federal, através da Lei $n^{\circ} 12.715$ de 17 de dezembro de 2012, instituiu o Programa de Incentivo à Inovação Tecnológica e Adensamento da Cadeia Produtiva de Veículos Automotores - INOVAR-AUTO com o objetivo de apoiar o desenvolvimento tecnológico, a inovação, a segurança, a proteção ao meio ambiente, a eficiência energética e a qualidade dos automóveis, caminhões, ônibus e autopeças. No entanto, as empresas adotam tais políticas públicas quando é possível avaliar os ganhos obtidos com sua implantação. Deste modo, esta pesquisa apresenta a aplicação da Teoria das Opções Reais (TOR) na avaliação da política pública de Incentivo à Inovação Tecnológica e Adensamento da Cadeia Produtiva de Veículos Automotores. A abordagem modela a tomada de decisão como uma opção de compra americana em um projeto de instalação de uma unidade produtora de veículos automotores que deseja aderir ao INOVAR-AUTO. Os resultados apontam que não é interessante para a empresa adotar tal política, para o prazo estipulado de cinco anos.
\end{abstract}

Palavras-chave: Inovar-Auto. Tomada de decisão. Teoria das Opções Reais (TOR).

Abstract: The automotive industry moves a huge chain that includes manufacturers and suppliers, gas stations, insurance companies, auto repair shops, tire stores, media companies, advertising agencies, among others. Aware of this importance the federal government through the Law No. 12715 of 17 December 2012 establishing a Programme to Encourage Innovation and Densification of the Productive Chain of Motor Vehicles - INOVAR-AUTO in order to support technology development, innovation, safety, environmental protection, energy efficiency and the quality of cars, trucks, buses and auto parts. As a specific goal, it demonstrated the importance of the automotive sector in the Brazilian economic context. Therefore, an exploratory and documentary literature on the subject was held as well as a case study in a car company from Japan. Therefore, the companies take public politician whenever they can measure gain from implementation of then. Likewise, this research shows Real Options Theory's application as it is in the Public politician of Programme to Encourage Innovation and Densification of the Productive Chain of Motor Vehicles. The model for taking decision follows the American way in a project for an factory installation for vehicles which wants join to INOVAR AUTO. The results show that it is not interesting for the company to adopt such a policy for the stipulated period of five years.

Keywords: Inovar-Auto. Decision making. Real Options Theory. 


\section{INTRODUÇÃO}

Mundialmente a indústria automobilística é reconhecida como uma das alavancas da economia (Oliveira e Rocha, 2014). No Brasil não poderia ser diferente, justificada pela ascensão que o segmento obteve a partir de 2006, quando o Brasil era apenas o décimo colocado no ranking automotivo mundial e ao final de 2010 o quarto colocado em unidades vendidas, atrás apenas da China, dos Estados Unidos e do Japão (MARIANI, 2012).

No cenário da crise financeira internacional que se intensificou no Brasil no final de 2008, foi um dos setores (além dos produtos da linha branca) beneficiados com os incentivos fiscais com a redução do Imposto sobre Produtos Industrializados (IPI). A intenção com a desoneração do IPI era de aumentar o consumo dos produtos no mercado interno para preservar o equilíbrio econômico e evitar uma recessão, mantendo com isso o nível da atividade produtiva e, consequentemente, dos empregos (ALVES; WILBERT, 2014).

Desde então o Governo Federal prorrogou por sucessivas vezes a redução da alíquota do IPI e mais recentemente criou por meio da Lei $n^{\circ} 12.715$ de 17 de dezembro de 2012 o Programa de Incentivo à Inovação Tecnológica e Adensamento da Cadeia Produtiva de Veículos Automotores (Inovar-Auto) com o objetivo de apoiar o desenvolvimento tecnológico, a inovação, a segurança, a proteção ao meio ambiente, a eficiência energética e a qualidade dos automóveis, caminhões, ônibus e autopeças.

Por meio deste Programa, que faz parte do chamado "Plano Brasil Maior", o Governo Federal concederá às empresas habilitadas, crédito presumido de IPI de até 30 pontos percentuais, desde que estas empresas estimulem e invistam na inovação, pesquisa e desenvolvimento no Brasil.

A adoção ou não da política pública, Inovar-Auto, constitui um direito e não uma obrigação, sendo que as empresas automotivas investem para implementar os requisitos para usufruir os direitos de tal política. Tais investimentos, dentro da análise de orçamentação de capital, são realizados se o retorno para a empresa for superior aos investimentos. No entanto, a análise deve incorporar todas as fontes de riscos do projeto, sendo esta uma análise estocástica.

Segundo vários autores (ANAMARI-BEATRICI, 2014; AZEVEDO e PAXSON, 2014; DAMARAJU et al., 2015; HORN et al., 2015), a Teoria das Opções Reais (TOR) 
constitui um dos métodos mais utilizados para avaliação de investimentos com as características citadas. Existem diversas publicações com a aplicação da TOR, podendo-se citar: mercados regulados (GUTHRIE et al., 2012) e avaliação de investimentos em distribuição de energia elétrica (Noronha, 2012); desenvolvimento de novos produtos (NORONHA et al., 2014), no entanto, na adoção de políticas públicas para o setor automotivo, a literatura é escassa.

Deste modo, o objetivo da pesquisa é aplicar a Teoria das Opções Reais para a tomada de decisão em investir e adotar a política pública Inovar-auto para o setor automotivo, considerando as incertezas e fontes de risco do mercado automotivo brasileiro. A pesquisa desenvolvida é quantitativa, cujo método de abordagem é a modelagem e simulação. Por meio da análise bibliométrica, nos sites periódicos da Capes (www.periodicos.capes.gov.br) e Scopus (www.scopus.com), tendo como palavra-chave Inovar-Auto foram encontrados doze artigos publicados nos seguintes periódicos: Techinical Papers, International Journal of Automotive Technology and Management (SAE) e Advances in Information and Communication Technology (IFIP). Com a análise bibliométrica, é possível definir as questões da pesquisa:

- é rentável para uma empresa investir recursos para a construção de uma nova planta para produção de automóveis, seguindo os requisitos do Inovar-Auto, e capitalizando os benefícios?

- a Teoria das Opções Reais é capaz de analisar o investimento na política pública, considerando a flexibilidade do investidor frente a decisão de adotar ou não a política pública, considerando outras oportunidades para investir?

$\mathrm{O}$ artigo está dividido em cinco seções. Na primeira é realizada a introdução da pesquisa, com enfoque nos objetivos e justificativas para a escolha do tema opções reais e avaliação de investimentos em políticas públicas. A caracterização do setor automobilístico brasileiro é apresentada na segunda seção. Deste modo, são abordados o desenvolvimento histórico da indústria automobilística e sua importância na economia brasileira. O programa de incentivo à inovação tecnológica da cadeia de veículos automotores é apresentado, sendo discutidos os benefícios e os investimentos necessários para a adesão ao programa INOVAR-AUTO. Na terceira seção é apresentada a TOR, destacando os tipos de opções com enfoque no mercado de ações. Além disso, são discutidos os modelos de precificações de ações: Modelo Black Scholes e o Binomial. A quarta seção apresenta a tomada de decisão em adotar 
a política pública Inovar-Auto modelado como uma opção americana de compra composta com uma de abandono. Na verdade, a opção de investir e construir uma nova planta seguindo os requisitos do Inovar-Auto corresponde a uma opção real de expansão. Como o investimento é realizado em mais de um período, dado que foi feito o investimento inicial a empresa adquire o direito mais não uma obrigação de aderir ao programa, podendo não aderir ao inovar e vender seus ativos. Na quinta seção é apresentada as conclusões e sugestões para futuras pesquisas.

\section{A INDÚSTRIA AUTOMOBILÍSTICA NO CONTEXTO ECONÔMICO BRASILEIRO}

A produção brasileira de autoveículos quase quadruplicou nos últimos 20 anos. Em 1991, foram fabricadas mais de 960 mil unidades no país, enquanto que em 2010 foram produzidos mais de 3,6 milhões de veículos; em 2013 foram produzidos mais de 3,7 milhões de veículos (BARROS; PEDRO, 2015). Desde a sua implantação, segundo a Anfavea (2016), o setor já produziu a expressiva cifra de 73,7 milhões de autoveículos montados.

Os indicadores econômicos da indústria automotiva traduzem a dimensão deste importante ramo industrial. Conforme relatório anual da Anfavea (2016), o mercado brasileiro é o quarto maior do mundo e apresentou um faturamento de US\$ 95,5 bilhões em 2014, o que corresponde a 20,4\% do PIB industrial brasileiro do ano de 2014. Os investimentos no setor, no período de 1994-2012 somaram US $\$ 68,0$ bilhões. O resultado desse investimento se traduz em sessenta e cinco fábricas instaladas em cinquenta e um Municípios, e estes localizados em onze Estados da Federação. Ademais, o Brasil é o $8^{\circ}$ produtor mundial de automóveis, com produção de 3,146 milhões (automóveis, comerciais leves, caminhões e ônibus) e gerou $R \$$ 178,5 bilhões de tributos em 2013.

O quadro 1 traz os principais indicadores deste segmento. Verifica-seque as importações do setor são significativas. Em 2015 foram importados US\$ 22,4 bilhões, entre automóveis, máquinas agrícolas e autopeças, gerando um saldo comercial negativo de US $\$ 5,5$ bilhões. 
Quadro 1 - A indústria automobilística brasileira em números

\begin{tabular}{|c|c|}
\hline \multicolumn{2}{|c|}{ Principais Indicadores do setor automotivo } \\
\hline \multirow{3}{*}{ Empresas } & Fabricantes: $\mathbf{3 1}$ \\
\hline & Autopeças: 624 \\
\hline & Concessionárias (2014):5.533 \\
\hline Fábricas & 65 unidades, 11 estados, 51 municípios \\
\hline \multirow{2}{*}{ Capacidade instalada } & Auto veículos: 4,5 milhões/ano \\
\hline & Máquinas agrícolas e rodoviárias: 109 mil (2012) \\
\hline Faturamento (2014) & US $\$ 95,5$ bilhões \\
\hline Investimento 1994-2012 & US $\$ 68,0$ bilhões \\
\hline \multirow{2}{*}{ Produção Acumulada } & Auto veículos montados: 73,7 milhões (1957-2015) \\
\hline & Máquinas agrícolas e rodoviárias: 2,5 milhões (1960-2015) \\
\hline \multirow{3}{*}{ Comércio Exterior (2015) } & Exportações: US $\$ 16,9$ bilhões \\
\hline & Importações: US\$ 22,4 bilhões \\
\hline & Saldo: (-) US $\$ 5,5$ bilhões \\
\hline Emprego direto e indireto & 1,5 milhões de pessoas \\
\hline \multirow{2}{*}{ Participação no PIB (2014) } & Industrial: $20,4 \%$ \\
\hline & Total: $\mathbf{4 , 1 \%}$ \\
\hline Geração de tributos (2013) & R $\$ 178,5$ bilhões \\
\hline Ranking mundial (2014) & Autoveículos: $8^{\circ}$ Produtor/4 mercado interno \\
\hline
\end{tabular}

De acordo com Barros e Pedro (2015), os veículos importados elevaram sua participação na frota brasileira nos últimos anos, com um share de $21,7 \%$ no total das vendas em 2010; principalmente a participação chinesa, o que suscitou preocupação do governo e das montadoras instaladas no Brasil. Deste modo, foi criado o Plano Brasil Maior (PBM) que tem como foco a inovação e o adensamento produtivo do parque industrial brasileiro, objetivando ganhos sustentados da produtividade do trabalho (BRASIL, 2015). Premissas na arquitetura do PBM consideram que o setor automotivo é não apenas estratégico, mas também prioritário (AUTOMOTIVE BUSINESS, 2011). Continuamente às medidas apresentadas pelo Plano Brasil Maior, em 2012 o governo anunciou a criação de um novo regime automotivo, o Inovar-Auto.

\subsection{Programa de incentivo à inovação tecnológica e adensamento da cadeia produtiva de veículos automotores - INOVAR-AUTO}

A crise financeira mundial iniciada no quarto trimestre de 2008 impactou significativamente o setor automotivo, pois em relação ao terceiro trimestre do mesmo ano as vendas caíram $23,7 \%$. Porém, no ano de 2008 a indústria automobilística bateu recorde de produção e vendas no país. O governo brasileiro atuou rapidamente, reduzindo o IPI incidente sobre os veículos e ampliando o crédito aos bancos das 
montadoras, o que surtiu efeito, pois já no primeiro trimestre de 2009 a produção e a venda estavam nos níveis do período pré-crise (BNDES, 2014).

Em substituição a política de redução de alíquotas do IPI (LEÃO; GOULART, 2014), o Governo Federal, por meio da Medida Provisória nº. 563/2012, regulamentada pelo Decreto $\mathrm{n} \times$. 7.716/12, convertida na Lei $\mathrm{n}$ ㅇ. 12.715/2012, regulamentada pelo Decreto nํ. 7.819/2012 institui o INOVAR-AUTO que entrou em vigor em Janeiro de 2013 com validade até 2017, prazo em que as empresas precisam voluntariamente se habilitar para gozarem dos incentivos previstos.

O intuído do Governo foi à substituição de veículos importados por outros fabricados no País (ANFAVEA, 2014), ou seja, aumentar a quantidade de processos locais e garantir mínimos de investimento e pesquisa e desenvolvimento na cadeia produtiva automotiva (LEÃO; GOULART, 2014).

O Governo Federal, por meio da Medida Provisória nํ․ 563/2012, regulamentada pelo Decreto $\mathrm{n} \cong$. 7.716/12, convertida na Lei $\mathrm{n} \div$. 12.715/2012, regulamentada pelo Decreto n‥7.819/2012 instituiu o Inovar-Auto que entrou em vigor em Janeiro de 2013 com validade até 2017, prazo em que as empresas precisam voluntariamente se habilitar para gozarem dos incentivos previstos.

Tem como objetivo apoiar o desenvolvimento tecnológico, a inovação, a segurança, a proteção ao meio ambiente, à eficiência energética e a qualidade dos veículos e das autopeças (Decreto n.7.819/12).

Para fruição do benefício às empresas deverão promover a habilitação junto ao Ministério do Desenvolvimento, Indústria e Comércio Exterior (MDIC), que terá validade de até doze meses e poderá ser renovada anualmente. São possíveis beneficiários as empresas que produzam ou tenham intenção de produzir ou comercializam os produtos classificados no capítulo 87 da Tabela do IPI (TIPI), os quais são: tratores, veículos automóveis para transporte de dez pessoas ou mais (incluindo o motorista) e veículos automóveis para cinco pessoas.

\subsubsection{Condições gerais}

Para se habilitarem ao programa, além da inscrição, as empresas deverão cumprir alguns requisitos gerais e outros específicos. Dentre os requisitos gerais, apresentam-se a regularidade da empresa em relação aos tributos federais e o 
compromisso da empresa de atingir níveis mínimos de eficiência energética em relação aos produtos comercializados no País.

De acordo com o decreto regulamentador do INOVAR-AUTO, entende-se como eficiência energética níveis de autonomia expressos em quilômetros por litro de combustível $(\mathrm{km} / \mathrm{l})$ ou níveis de consumo energético expressos em megajoules por quilômetro $(\mathrm{MJ} / \mathrm{km})$, medidos segundo o ciclo de condução combinado descrito na Norma ABNT NBR 7024:2010 e segundo as instruções normativas complementares do Instituto Brasileiro do Meio Ambiente (IBAMA) para veículos híbridos e elétricos.

O compromisso de eficiência energética não se aplica as empresas que produzam ou comercializem, no País, exclusivamente veículos pesados, p.ex. ônibus, caminhões.

A habilitação ao Inovar-Auto é condicionada ao cumprimento dos requisitos a seguir:

1) realização pela empresa, no País, de atividades fabris e de infraestrutura de engenharia diretamente ou por terceiros;

2) realização pela empresa, no País, de investimentos em pesquisa, desenvolvimento e inovação, diretamente ou por terceiros;

3) realização pela empresa, no País, de dispêndio em engenharia, tecnologia industrial básica e de capacitação de fornecedores, diretamente ou por terceiros;

4) adesão da empresa a programa de etiquetagem veicular de âmbito nacional, nos termos de regulamento, exceto quanto aos veículos com motor de pistão, de ignição por compressão (diesel ou semidiesel).

A empresa deverá cumprir pelo menos 3 dos 4 requisitos estabelecidos acima, com exceção das fabricantes que produzam exclusivamente veículos com motor de pistão, de ignição por compressão (diesel ou semidiesel), as quais deverão cumprir pelo menos 2 dos requisitos estabelecidos nos itens 1 a 3 .

\subsubsection{Benefícios}

As empresas habilitadas farão jus a crédito presumido do IPI, conforme as seguintes definições: 
Crédito presumido do IPI com base nos dispêndios realizados em cada mêscalendário relativos a insumos estratégicos e ferramentaria apurados com base na multiplicação dos valores dos dispêndios realizados, pelos seguintes fatores:

Tabela 1 - Fator a ser aplicado para geração de crédito presumido de IPI

\begin{tabular}{cc}
\hline \multicolumn{2}{c}{ Automóveis e Comerciais Leves } \\
\hline Fator & Ano-Calendário \\
1,30 & 2013 \\
1,25 & 2014 \\
1,15 & 2015 \\
1,10 & 2016 \\
1,00 & 2017 \\
\hline
\end{tabular}

Fonte: Decreto n. 7.819/2012

Crédito presumido do IPI com base nos dispêndios realizados em cada mêscalendário relativos pesquisa, desenvolvimento tecnológico, inovação tecnológica e recolhimentos ao Fundo Nacional de Desenvolvimento Científico e Tecnológico (FNDCT), corresponderá a cinquenta por cento dos dispêndios, limitados ao valor que corresponder a aplicação de dois por cento da receita bruta total de venda de bens e serviços, excluídos os impostos e contribuições incidentes sobre a venda.

Crédito presumido do IPI com base nos dispêndios realizados em cada mêscalendário relativos capacitação de fornecedores e engenharia e tecnologia industrial básica, corresponderá a cinquenta por cento do valor dos dispêndios que excederem a setenta e cinco centésimos por cento, até o limite de dois inteiros e setenta e cinco centésimos por cento, da receita bruta total de venda de bens e serviços, excluídos os impostos e contribuições incidentes sobre a venda. $\mathrm{O}$ quadro 2 apresenta um resumo do crédito presumido que as montadoras habilitadas no programa poderão utilizar para abater dos 30 p.p. do IPI.

\begin{tabular}{|c|c|c|c|c|c|}
\hline & 2013 & 2014 & 2015 & 2016 & 2017 \\
\hline $\begin{array}{l}\text { 1. insumos estratégicos } \\
\text { 2. ferramentaria }\end{array}$ & 1,30 & 1,25 & 1,15 & 1,10 & 1,00 \\
\hline $\begin{array}{l}\text { 3. pesquisa } \\
\text { 4. desenvolvimento tecnológico } \\
\text { 5. inovação tecnológica } \\
\text { 6. recolhimentos ao Fundo Nacional de } \\
\text { Desenvolvimento Científico e Tecnológico - } \\
\text { FNDCT }\end{array}$ & \multicolumn{5}{|c|}{$\begin{array}{c}\text { corresponder a aplicação de } \mathbf{2} \% \text { da receita bruta total de venda de bens e serviços, excluídos os impostos } \\
\text { e contribuições incidentes } \\
\text { sobre a venda. }\end{array}$} \\
\hline $\begin{array}{l}\text { 7. capacitação de fornecedores } \\
\text { 8. engenharia e tecnologia industrial básica }\end{array}$ & \multicolumn{5}{|c|}{$\begin{array}{l}\text { excederem a } 0,75 \% \text {, até o limite de } 2,75 \% \text {, da receita bruta total de } \\
\text { venda de bens e serviços, excluídos os impostos e contribuições incidentes sobre a venda. }\end{array}$} \\
\hline
\end{tabular}

Fonte: Decreto n. 7.819/2012 - Adaptado pelo autor 


\section{A TEORIA DAS OPÇÕES REAIS E O INOVAR-AUTO}

Para Fabrini (2011), uma opção real constitui o direito, mas não a obrigação de empreender uma ação, tais como: expandir, abandonar ou diferir, sobre um determinado projeto, a um custo pré-determinado, denominado preço de exercício, por um período estabelecido, denominado duração da opção real. Do mesmo modo que as opções financeiras, as opções reais dependem de cinco variáveis básicas (COPELAND; ANTIKAROV, 2001):

i. Valor do ativo subjacente sujeito a risco (S): o ativo subjacente pode ser um projeto ou investimento, cujos retornos são incertos devido a várias fontes de incerteza;

ii. Preço de exercício $(\boldsymbol{X})$ : o preço de exercício corresponde ao o montante monetário investido para exercer a opção, se estiver "comprando" o ativo, ou o montante recebido, se estiver "vendendo" o ativo;

iii. Prazo de vencimento da opção ( $T$ ): tempo compreendido entre a aquisição da opção e seu exercício. Com o aumento do prazo de expiração, o valor da opção também aumenta;

iv. Desvio padrão do valor do ativo subjacente sujeito a risco (o): o desvio padrão mede a dispersão do valor do ativo, decorrente das fontes de risco. $\mathrm{Na}$ verdade, o desvio padrão corresponde a volatilidade do valor do ativo. O valor de uma opção aumenta com o risco do ativo subjacente, porque os retornos de uma opção dependem do valor do ativo subjacente que está acima do preço de exercício, e a probabilidade disto aumenta com a volatilidade do ativo subjacente;

v. Taxa de juros livre de risco ao longo da vida da opção $(r)$ : a taxa de retorno que pode ser obtida sem que o investidor assuma riscos corresponde a taxa livre de risco.

As opções podem ser classificadas como opções de compra, denominada Call (dá o direito ao seu detentor de comprar um ativo objeto a um preço pré-determinado) ou de venda, Put, (dá o direito ao seu detentor de vender um ativo objeto a um preço pré-determinado). As opções são classificadas como americanas quando podem ser 
exercidas até a data de vencimento. Já as ser europeias só podem ser exercidas na data de vencimento (COPELAND; ANTIKAROV, 2001).

Noronha (2012) apresenta os seguintes tipos de opções:

- A opção de espera ou de timing de investimento: tais opções garantem ao gerente a flexibilidade de considerar o adiamento do projeto, aguardando por melhores configurações do mercado e/ou novas informações. Contudo, quando o projeto é muito atrativo, a espera deixa de ter valor e o projeto dever ser iniciado imediatamente para obter o fluxo de caixa.

- A opção de abandono: é a opção aplicada em projetos que estão em operação, ou que estão parados temporariamente. Quanto maior a flexibilidade de uso alternativo de recursos do projeto, mais valiosa será essa opção. Adicionalmente, o valor da opção cresce com o valor residual obtido com a venda dos ativos, com o aumento da volatilidade do projeto e com a ampliação da vida útil do projeto Brasil (2002). A opção de abandono de um projeto por um preço fixo (mesmo que esse preço decline com o tempo) é formalmente uma opção de venda americana.

- A opção de expansão (crescimento ou investimentos sequenciais): é a modelagem mais utilizada em projetos pilotos e em projetos de pesquisa e desenvolvimento (P\&D). Sua consideração busca quantificar o aspecto estratégico de um projeto. As opções de expansão, criadas pelos investimentos, adicionam valor corporativo. Existem situações em que a análise tradicional fornece um Valor Presente Líquido negativo e a modelagem por opção de expansão torna o projeto viável. Isto ocorre porque o projeto permite investir uma parte pequena do montante do investimento total podendo-se obter informações de mercado e, caso as mesmas sejam favoráveis (lado "bom" da incerteza) originar investimentos de maior porte em projetos atrativos e com reduzida incerteza técnica. Caso as informações sejam desfavoráveis (lado "ruim" da incerteza), o gerente simplesmente não investirá nas etapas subsequentes. Para AnamariBeatrice (2014), a opção de expansão de um projeto, pagando-se mais para aumentá-lo, é uma opção de compra americana.

- Opção de parada temporária: este tipo de opção é aplicável quando existe a esperança de voltar a produzir economicamente. $O$ custo de 
desmobilização temporária, o custo de preservação, e o custo de retomada da produção são fatores determinantes nesse tipo de decisão. Eventualmente esses custos podem ser muito elevados, de forma a ser preferível o abandono definitivo.

- Opção de redução de escala produtiva, em função de novos dados de mercado e/ou de custos operacionais convexos, que podem exigir otimizações de escala para maximizar o lucro. A redução de escala pode não só reduzir o custo operacional, como obter um valor residual de parte dos equipamentos a serem desativados;

- Opção de tempo de construção (time to build): Este tipo de opção é utilizado em projetos que demandam vários anos de construção, como por exemplo, usinas hidrelétricas e grandes obras públicas. Tais projetos apresentam flutuações no preço do produto ou no custo de construção podem levar a uma paralisação temporária da construção do projeto.

\subsection{Método de avaliação das opções}

Segundo Noronha (2012), o preço do ativo objeto de uma opção tem um comportamento estocástico contínuo, na forma de um Movimento Geométrico Browniano (MGB) de acordo com a equação 1.

$$
d S=\mu S d t+\sigma S d z
$$

O MGB nunca assume valores negativos sendo, portanto, adequado para representar o comportamento do preço de ativos financeiros. Assim, é assumido que os preços do ativo objeto em datas futuras calculados de forma contínua para um período entre duas datas são representados por uma distribuição probabilística lognormal e, consequentemente, as taxas de retorno do ativo objeto seguem uma distribuição normal. O termo $d z$ é um incremento do processo estocástico, definido por $d z=\varepsilon \sqrt{d t}$, sendo que $\varepsilon$ tem uma distribuição normal padrão.

Segundo Santos et al. (2014), uma carteira formada por tais ativos possui um Valor Presente no tempo $t, V_{t}$, e o valor da oportunidade de investimento $F\left(V_{t}\right)$ deve satisfazer a equação 2 . 


$$
\frac{\partial F}{\partial t}+\frac{1}{2} \sigma^{2} V^{2} \frac{\partial^{2} F}{\partial V^{2}}+r V \frac{\partial F}{\partial V}-r F=0
$$

A resolução da equação parcial diferencial, EDP, fornece o valor da opção real, $V_{O R}$, o qual somado ao VPL fornece o valor de um projeto com flexibilidade. Existem duas abordagens para a resolução da EDP e definição do valor da opção: BlackScholes e a árvore binomial (NORONHA, 2012; ZEE; SPINLER, 2014; SHIBATA; NISHIHARA, 2015).

\subsubsection{Modelo Black-Scholes}

A avaliação de opções pelo método desenvolvido por Black e Scholes consiste em um método analítico para solução da equação diferencial parcial, sob determinadas condições:

- É possível recorrer a uma taxa de juros sem qualquer risco durante o tempo de vida da opção (capitalização contínua);

- Não existem quaisquer custos de transação associados à gestão de uma carteira constituída por opções e seus ativos financeiros subjacentes;

- Não existem possibilidades de arbitragem;

- A transação do ativo financeiro se faz em tempo contínuo;

- O ativo financeiro é divisível;

- O ativo financeiro não dá dividendos durante o tempo de vida da opção;

- É permitido o short selling, ou seja, vender ou assumir o compromisso de vender ativos financeiros que não se possui até certo momento.

Para o caso de uma opção europeia do tipo call, a equação diferencial é representada pela equação 3 :

$$
\frac{\partial C}{\partial t}(t, S)+\frac{1}{2} \sigma^{2} S^{2} \frac{\partial^{2} C}{\partial S^{2}}(t, S)+r S \frac{\partial C}{\partial S}(t, S)-r C(t, S)=0
$$

sendo $t \geq 0$ e $S>0$

A condição para a opção europeia de compra é $C(T, S)=\operatorname{Max}(S-X, 0)$. Nas situações extremas, ou seja, quando $S$ tende a zero, $\lim _{S \rightarrow 0^{+}} C(t, S)=0$. Por outro lado, quando $S$ é muito grande, $\lim _{S \rightarrow 0^{+}} C(t, S)=E e^{-r(T-t)}$. Esta abordagem inclui quatro parâmetros dimensionais: $o^{2}, r, T$ e $E$. 
Um possível método para a solução da equação de Black-Scholes consiste em tornar constante os coeficientes da equação que dependem do valor da variável independente $S$. Deste modo, para $t=T-\left(\frac{2}{\sigma^{2}}\right) \tau \quad ; S=E e^{x} \quad ; C(t, S)=E v(\tau, x)$. A equação diferencial resulta na equação 4 .

$$
\frac{\partial v}{\partial \tau}(\tau, x)=\frac{\partial^{2} v}{\partial x^{2}}(\tau, x)+(c-1) \frac{\partial v}{\partial x}(\tau, x)-c v(\tau, x)
$$

Sendo $c=\left(\frac{2 r}{\sigma^{2}}\right)$ um parâmetro adimensional e a condição final $t=T$ passa a ser uma condição inicial $\tau=0$, resultando em $v(0, x)=\max \left\{e^{x}-1,0\right\}$.

Quando se converte a equação de Black-Scholes (a coeficientes constantes) na forma canônica, chega-se a equação de difusão. Para isto, é necessário realizar uma transformação apenas na variável dependente, de acordo com a equação 5.

$$
v(\tau, x)=e^{\alpha x+\beta \tau} u(\tau, x)
$$

A estratégia consiste em escolher $\alpha$ e $\beta$ de forma anular alguns termos, para isto é necessário satisfazer as equações 6 e 7 :

$$
\begin{gathered}
0=2 \alpha+c-1 \\
\beta=\alpha^{2}+(c-1) \alpha-c
\end{gathered}
$$

A solução para a equação diferencial, através de um problema de valor inicial é a equação 8 , que é a equação de avaliação de uma opção de compra europeia pelo método de Black-Scholes.

$$
C(t, S)=S N\left(d_{1}\right)-X e^{-r t} N\left(d_{2}\right)
$$

Sendo:

$$
d_{1}=\frac{\ln \left(\frac{S}{X}\right)+\left(r+\frac{1}{2} \sigma^{2}\right) T}{\sigma \sqrt{T}}
$$




$$
d_{2}=\frac{\ln \left(\frac{S}{X}\right)+\left(r-\frac{1}{2} \sigma^{2}\right) T}{\sigma \sqrt{T}}
$$

$N\left(d_{i}\right)=$ Probabilidade de uma variável aleatória, de distribuição normal padronizada, ser menor ou igual a $d_{i}(i=1,2)$.

\subsubsection{Modelo Binomial}

Para Ross et al. (2002), a avaliação e tomada de decisão utilizando a teoria das opções reais deve considerar a incerteza no valor do projeto durante o tempo. A figura 1 apresenta as etapas para avaliação de projetos através da teoria de opções reais, pelo método binomial. Na verdade, um projeto requer um investimento, I, gerando valores de fluxos de caixa, na data posterior ao investimento até o final do projeto, que são variáveis aleatórias, de uma forma genérica, $F C_{t}$, considerando-se uma taxa de juros, $j$.

Figura 1 - Avaliação de investimento aplicando opções reais por meio do método binomial

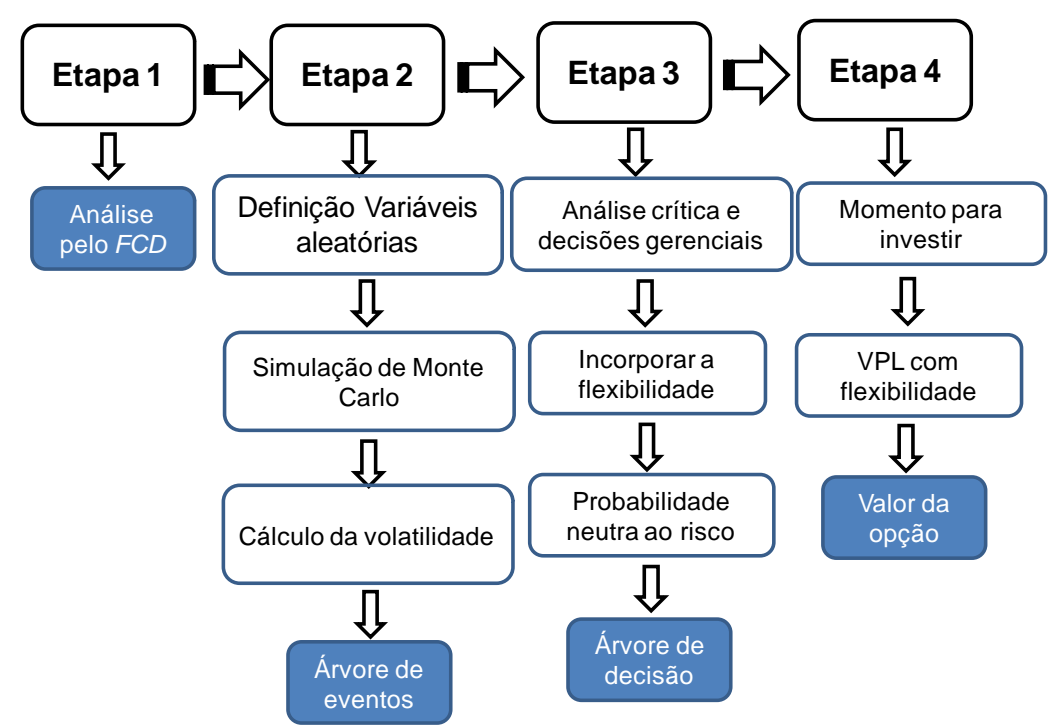

Fonte: Brandão (2010, p.5)

De acordo com a figura 2, o fluxo de caixa apresenta comportamento aleatório e, portanto, o valor do projeto, $V P$, é uma variável aleatória, sendo possível determinar o retorno do projeto em qualquer período $t$. $O$ valor do projeto em qualquer data $t$ pode 
ser escrito como uma variável aleatória, seguindo um modelo de Movimento Geométrico Browniano (MGB), com a taxa de retorno sendo uma variável aleatória, normalmente distribuída, com média $\mu T$ e variância $o^{2} T$.

Figura 2 - Fluxo de caixa aleatório de um projeto

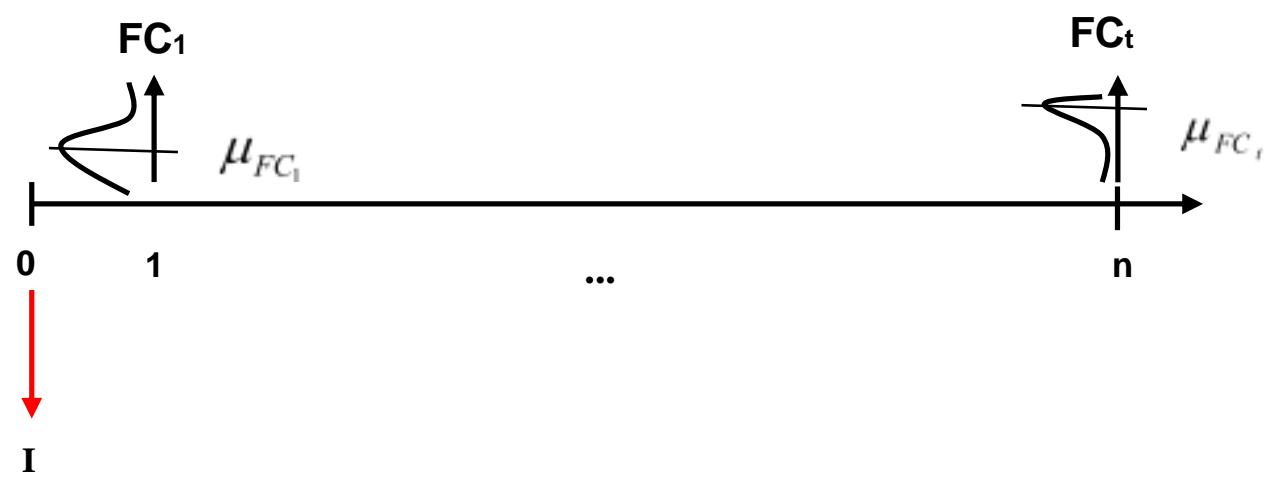

Quando se aplica as etapas do modelo binomial, tem-se (BRASIL, 2004; BRANDÃO, 2010):

Etapa 1: Análise pelo método do fluxo de caixa descontado: Geralmente, se utiliza o critério do VPL.

Etapa 2: Definição das variáveis aleatórias: conforme pode ser observado na figura 2, os fluxos de caixa para os períodos são afetados pela incerteza e desta forma são variáveis aleatórias. Um exemplo seria a incerteza no preço e na quantidade vendida em um projeto de expansão industrial, tais variáveis são variáveis aleatórias e induzem à aleatoriedade no fluxo de caixa por período. Na verdade, a questão é que novas informações de mercado, levam a incertezas no valor do projeto, com valores acima e abaixo de um valor base, $\mathrm{VP}_{0}$, determinado pela equação 11 .

$$
V P_{0}=\sum_{t=1}^{n} \frac{F C_{t}}{(1+i)^{t}}
$$

Para a abordagem binomial é possível determinar o sistema de equação, dado pela equação 12:

$$
\begin{aligned}
& n[p \ln (u)+(1-p) \ln (d)]=\mu T \\
& n p(1-p)[\ln (u)+\ln (d)]^{2}=\sigma^{2} T
\end{aligned}
$$


Como são desconhecidas três variáveis e existem duas equações, existem múltiplas soluções, sendo a equação 13 uma possível.

$$
\begin{aligned}
& u=e^{\sigma \sqrt{t}} \\
& d=e^{-\sigma \sqrt{t}} \\
& p=\frac{1}{2}+\frac{1}{2}\left(\frac{\mu}{\sigma}\right) \sqrt{t}
\end{aligned}
$$

Sendo $t$ a razão entre a maturidade da opção e o número de estágios da árvore e o a volatilidade do Valor Presente (VP) do fluxo de caixa, determinado por meio da Simulação de Monte Carlo.

Etapa 3: Com a árvore de eventos definida a próxima etapa consiste em realizar as análises críticas e gerenciais para se obter a árvore de decisões. Segundo Noronha (2012), a análise a ser feita é backward em cada etapa da árvore para determinar o valor do projeto e da opção. Na última coluna da árvore de eventos, a opção de investimento em uma fase do empreendimento pode ser interpretada como uma opção de compra americana em que o preço de exercício $X$ é equivalente ao valor do investimento a ser feito. Numa opção americana a decisão de pode ser tomada a qualquer momento dentro do período de análise. Assim, para cada célula da última coluna, o valor da opção é dado pelo valor máximo entre o Valor Presente menos o investimento e zero, ou seja, Máximo (VP-X;0). Simultaneamente é definida a árvore de decisão, ou seja, se for uma opção americana de compra, só faz sentido investir se o VP for maior que o preço do exercício $(X)$. Para os demais nós da árvore, é utilizado o método do portfólio replicado para estimar o valor da opção, $V_{O R}$, dado pela equação 14.

$$
V_{O R}=\operatorname{Max}[V P-X ; \text { Portfólio }]
$$

sendo: Portfolio $=m V P+B$

O portfólio replicado consiste em $m$ unidades do ativo replicante e $B$ unidades do título de dívida sem risco. Ao se considerar $C_{u}$ e $C_{d}$ o valor da opção na situação de preços ascendentes e descendentes, respectivamente, $V_{u}$ e $V_{d} \mathrm{O}$ valor do ativo objeto, também na situação ascendente e descendente é possível obter o sistema de equações 15. 


$$
\left\{\begin{array}{l}
m V_{u}+B\left(1+r_{f}\right)=C_{u} \\
m V_{d}+B\left(1+r_{f}\right)=C_{d}
\end{array}\right.
$$

Uma solução para o sistema é a seguinte:

$$
\begin{aligned}
& m=\frac{C_{u}-C_{d}}{V_{u}-V_{d}} \\
& B=\frac{C_{u}-m V_{d}}{\left(1+r_{f}\right)}
\end{aligned}
$$

\section{A TEORIA DAS OPÇõES REAIS APLICADA A AVALIAÇÃO DA POLÍtICA PÚBLICA}

A empresa $A$ é uma multinacional, com aproximadamente mil e oitocentos colaboradores, localizada no sul fluminense. A construção da planta se iniciou em dois mil e doze e foi inaugurada em 2014. As informações a respeito do projeto foram obtidas por meio do Guia Setorial da Indústria Automobilística Brasileira (ANFAVEA, 2015) e de pesquisa documental na empresa.

O projeto de investimento consiste em uma expansão da empresa $A$, com uma nova planta em Resende, com capacidade anual de duzentos mil carros e duzentos mil motores. O investimento a ser realizado é de $R \$ 2,6$ bilhões, sendo o gasto com instalações e equipamentos, o terreno foi doado. No entanto, o investimento considerando a produção de veículos é de $\mathrm{R} \$ 2,24$ bilhões, divididos em três anos, totalizando vinte e três meses necessários para inauguração da planta, conforme mostra a tabela 2.

Tabela 2 - Distribuição do capital investido em relação aos anos

\begin{tabular}{cc} 
Ano & Investimento \\
\hline 2012 & $\mathrm{R} \$ 1.106 .517 .891,50$ \\
2013 & $\mathrm{R} \$ 1.000 .000 .000,87$ \\
2014 & $\mathrm{R} \$ 320.869 .565,22$ \\
\hline
\end{tabular}

Fonte: Elaborado pelo autor

O portfólio de produtos da empresa é composto por dois modelos de veículos, e a participação no mercado é estimada em $2 \%$ (1,23\% para o produto $A$ e $0,77 \%$ para o produto $B$ ) nos dois primeiros anos do projeto e $5 \%$ para os demais anos. É esperado que o mercado atinja um total de dois milhões setecentos e setenta e dois mil e 
oitocentos e cinquenta unidades. O valor de venda dos dois produtos é apresentado na tabela 3. Cabe destacar que os produtos apresentam preço diferenciado, conforme a empresa adota ou não o Inovar-Auto:

Tabela 3 - Preço dos produtos

\begin{tabular}{ccc}
\hline Estratégia & Produto A & Produto B \\
\hline Com Inovar-Auto & $\mathrm{R} \$ 32.966,85$ & $\mathrm{R} \$ 38.462,84$ \\
Sem Inovar-Auto & $\mathrm{R} \$ 38.476,55$ & $\mathrm{R} \$ 44.891,07$ \\
\hline
\end{tabular}

Fonte: Site da Empresa A

\subsection{Cálculo da receita bruta de vendas}

A receita bruta de vendas é calculada a partir do portfólio de produtos fornecidos pela empresa. Neste caso, para os dois produtos a receita bruta, $R B_{j}$, para um ano $j$ (j>0) é dada pela equação 16 :

$$
R B_{j}=Q\left(q_{A} p_{A}+q_{B} p_{B}\right)
$$

Sendo $Q$ a projeção das vendas; $p_{A}$ o preço do produto $A$ e $p_{B}$ o preço do produto $B$ e as variáveis $q_{A}$ e $q_{B}$, respectivamente a participação no mercado do produto $A$ e $B$. Deste modo, para o ano de 2014, substituindo $Q=2.794 .687$; $p_{A}=R \$ 32.966,85$; $p_{B}=R \$ 38.462,84 ; q_{A}=1,23 \%$ e $q_{B}=0,77 \%$ a receita bruta é:

$$
R B_{2014}=\mathrm{R} \$ 1,96 \text { bilhões }
$$

\subsection{Cálculo das deduções}

Da Receita Bruta é deduzido o Imposto sobre Operações de Circulação de Mercadoria e sobre Prestação de Serviços e Transportes (ICMS), o Programa de Integração Social (PIS) e a Contribuição para Financiamento da Seguridade Social (COFINS), totalizando $24 \%$.

Para o cálculo do Imposto sobre Produtos Industrializados, IPI, os passos a seguir são os seguintes:

1. Dados os preços de dois veículos, carro $A$ e carro $B$, respectivamente: $\mathrm{R} \$$ $50.000,00$ e $\mathrm{R} \$ 40.000,00$;

2. Com as alíquotas de $37 \%$ e $7 \%$ deve se determinar qual o valor da parcela de IPI a ser pago; 
3. Nesta fase, são contabilizados os insumos estratégicos comprados no Brasil, sendo respectivamente $R \$ 10.000,00$ e $R \$ 13.000,00$;

4. De acordo com a adesão a política, é obtido o fator de multiplicação, sendo neste caso, 1,10;

5. O valor a ser obtido nas contas é apurado, multiplicando o fator de multiplicação pelos insumos estratégicos comprados no Brasil. Para o carro $A$, é de $\mathrm{R} \$ 11.000,00(1,10 \times 10.000,00)$;

6. O valor de IPI a ser pago é igual a soma do IPI a $7 \%$ com o cancelamento de IPI a 30\%. Para o $A$, o IPI a ser pago é de $\mathrm{R} \$ 4.500,00$ $(3.500,00+1.000,00)$. A tabela 4 apresenta os resultados com o roteiro dos cálculos realizados.

7.

Tabela 4 - Determinação da redução do IPI

\begin{tabular}{|c|c|c|c|c|c|}
\hline & & A & & B & \\
\hline Preço & & $50.000,00$ & [1] & $40.000,00$ & [1] \\
\hline IPI 7\% & {$[1]^{\star} 7 \%$} & $3.500,00$ & [2] & $2.800,00$ & [2] \\
\hline IPI 30\% & {$[1]^{\star} 30 \%$} & $15.000,00$ & & $12.000,00$ & \\
\hline \multirow[t]{2}{*}{ Fator de multiplicação (2016) } & & $\begin{array}{r}10.000,00 \\
1,10\end{array}$ & $\begin{array}{l}{[3]} \\
{[4]}\end{array}$ & $\begin{array}{r}13.000,00 \\
1,10\end{array}$ & $\begin{array}{l}{[3]} \\
{[4]}\end{array}$ \\
\hline & {$[3]^{*}[4]$} & $11.000,00$ & [5] & $14.300,00$ & [5] \\
\hline $\begin{array}{l}\text { Cancelamento de } 30 \% \mathrm{IPI} \\
\text { IPI a ser pago }\end{array}$ & $\begin{array}{l}{[3]-[5]} \\
{[2]+[6]}\end{array}$ & $\begin{array}{r}1.000,00 \\
4.500,00\end{array}$ & [6] & $2.800,00$ & \\
\hline
\end{tabular}

Fonte: Elaborado pelo próprio autor

\subsection{Cálculo dos custos e despesas e depreciação}

Os custos, as despesas e a depreciação foram obtidos diretamente com a empresa. Com todas as informações é possível determinar o fluxo de caixa do projeto. A tabela 5 apresenta o fluxo de caixa da implantação da planta, para um período de cinco anos, que é a vigência do programa Inovar-Auto. 
Tabela 5 - Fluxo de caixa do projeto para os cinco anos

\begin{tabular}{|c|c|c|c|c|c|c|}
\hline Descrição & 0 & 1 & 2 & 3 & 4 & 5 \\
\hline Receita Bruta & & & $\mathrm{R} \$ 1.960 .909 .245,42$ & $\mathrm{R} \$ 4.902 .273 .113,55$ & $\mathrm{R} \$ 4.902 .273 .113,55$ & $\mathrm{R} \$ 4.902 .273 .113,55$ \\
\hline IPI & & & $\mathrm{R} \$ 137.263 .647,18$ & $\mathrm{R} \$ 343.159 .117,95$ & $\mathrm{R} \$ 343.159 .117,95$ & $\mathrm{R} \$ 343.159 .117,95$ \\
\hline ICMS & & & $\mathrm{R} \$ 470.618 .218,90$ & $\mathrm{R} \$ 1.176 .545 .547,25$ & $\mathrm{R} \$ 1.176 .545 .547,25$ & $\mathrm{R} \$ 1.176 .545 .547,25$ \\
\hline receita liquida & & & $\mathrm{R} \$ 1.353 .027 .379,34$ & $\mathrm{R} \$ 3.382 .568 .448,35$ & $\mathrm{R} \$ 3.382 .568 .448,35$ & $\mathrm{R} \$ 3.382 .568 .448,35$ \\
\hline Custos e despesas & & & $\mathrm{R} \$ 980.454 .622,71$ & $\mathrm{R} \$ 2.451 .136 .556,77$ & $\mathrm{R} \$ 2.451 .136 .556,77$ & $\mathrm{R} \$ 2.451 .136 .556,77$ \\
\hline Depreciação & & & $\mathrm{R} \$ 172.2000 .000,00$ & $\mathrm{R} \$ 172.200 .000,00$ & $\mathrm{R} \$ 172.200 .000,00$ & $\mathrm{R} \$ 172.200 .000,00$ \\
\hline Lucro tributável & & & $\mathrm{R} \$ 200.372 .756,63$ & $\mathrm{R} \$ 759.231 .891,57$ & $\mathrm{R} \$ 759.231 .891,57$ & $\mathrm{R} \$ 759.231 .891,57$ \\
\hline Imposto de renda & & & $\mathrm{R} \$ 68.126 .737,25$ & $\mathrm{R} \$ 258.138 .843,14$ & $\mathrm{R} \$ 258.138 .843,14$ & $\mathrm{R} \$ 258.138 .843,14$ \\
\hline Investimento fixo & -R\$ 1.106.517.891,50 & -R $\$ 1.000 .000 .000,00$ & $-\mathrm{R} \$ 320.869 .565,22$ & & & \\
\hline Depreciação & & & $\mathrm{R} \$ 172.200 .000,00$ & $\mathrm{R} \$ 172.2000 .000,00$ & $\mathrm{R} \$ 172.200 .000,00$ & $\mathrm{R} \$ 172.200 .000,00$ \\
\hline \multicolumn{7}{|l|}{ Resultado não operacional } \\
\hline Valor residual & & & & & & $\mathrm{R} \$ 1.500 .000 .000,00$ \\
\hline Fluxo de caixa & -R\$1.106.517.891,50 & $-R \$ 1.000 .000 .0000,00$ & $-R \$ 16.423 .545,84$ & $\mathrm{R} \$ 673.293 .048,44$ & $\mathrm{R} \$ 673.293 .048,44$ & $\mathrm{R} \$ 2.173 .293 .048,44$ \\
\hline
\end{tabular}

Fonte: Elaborado pelo próprio autor

\subsection{Análise pelo fluxo de caixa descontado}

$\mathrm{Na}$ análise tradicional, a viabilidade empresarial é calculada por meio do Valor Presente líquido (VPL). O VPL pode ser calculado utilizando-se a equação 17:

$$
V P L=F C_{0}+\sum_{j=1}^{n} \frac{F C_{j}}{(1+i)^{j}}
$$

Sendo:

$F C_{0}$ - Investimento na data zero;

$F C_{j}$ - Fluxo de caixa do ano 1 até o final projeto;

$i$ - Taxa de desconto.

A taxa de desconto i é usada para descontar o fluxo de caixa futuros do projeto. Normalmente estas taxas refletem as expectativas do investidor em relação aos riscos assumidos com o projeto. Para a empresa $A$, a taxa de desconto foi obtida dos demonstrativos financeiros sendo igual à $13,25 \%$ ao ano com capitalização anual. Deste modo, o VPL é de $\mathrm{R} \$ 37.140 .152,48$, ou seja, o investimento é aconselhado, pois gera um retorno positivo para a empresa. No entanto, se for calculada a taxa interna de retorno, $T I R$, verifica-se que seu valor é de $13,75 \%$, ou seja, muito próximo do custo de capital da empresa não sendo tão rentável. Além disso, existem várias fontes de incerteza que possuem impacto na decisão sobre o investimento e que devem ser consideradas. 


\subsection{Aplicação da simulação de Monte Carlo e determinação da volatilidade}

Com a aplicação da simulação de Monte Carlo é possível determinar a volatilidade do projeto. A volatilidade do projeto é devida as fontes de incerteza e risco. Ao analisar as variáveis que compõem o fluxo de caixa, verifica-se que as variáveis que possuem um comportamento aleatório são: número de carros vendidos no país, participação da empresa no mercado, Preço $A$, Preço $B$ e taxa de juros. Na análise da volatilidade de projetos industriais, uma das principais dificuldades é obter a distribuição das variáveis aleatórias que compõe o fluxo de caixa (SHIBATA E NISHIHARA, 2015). Uma solução encontrada é verificar, junto aos especialistas qual a tendência para os valores de tais variáveis. No caso deste projeto, a Anfavea constitui o especialista no tocante ao mercado de veículos auto motores. Uma distribuição de probabilidade bem utilizada nestas situações é a Triangular. Portanto, a tabela 6 apresenta as variáveis aleatórias e a caracterização da distribuição.

Tabela 6 - Caracterização das distribuições

\begin{tabular}{lc}
\hline Variável aleatória & Caracterização \\
\hline Número de carros vendidos no país & Triangular $(1800000,2300000,2800000)$ \\
Participação da empresa no mercado & Triangular $(1,8 \%, 2 \%, 5 \%)$ \\
Preço $A$ & Triangular $(30000,32000,35000)$ \\
Preço $B$ & Triangular $(38000,40000,43000)$ \\
Taxa de juros & Triangular $(10 \%, 13 \%, 15 \%)$ \\
\hline
\end{tabular}

Fonte: Elaborado pelo próprio autor

Para facilitar a determinação da volatilidade, pode-se utilizar a abordagem consolidada da incerteza, conforme Antirakov e Copeland (2001). Deste modo, podese criar a variável aleatória z, que representa o retorno do projeto, dada por:

$$
z=\ln \left(\frac{V P_{1}}{V P_{0}}\right)
$$

Sendo:

$\mathrm{VP}_{1}-$ Valor presente dos fluxos de caixa na data 1

$\mathrm{VP}_{0}$ - Valor presente dos fluxos de caixa na data 0.

A simulação de Monte Carlo pode ser desenvolvida no Excel ${ }_{\circledast}$, no entanto, para esta pesquisa foi utilizada o software Crystal Ball®. A figura 3 apresenta o histograma 
da variável aleatória retorno $Z$, que a probabilidade de o retorno ser positivo é de aproximadamente $78 \%$.

Figura 3- Distribuição de probabilidade para o retorno $Z$

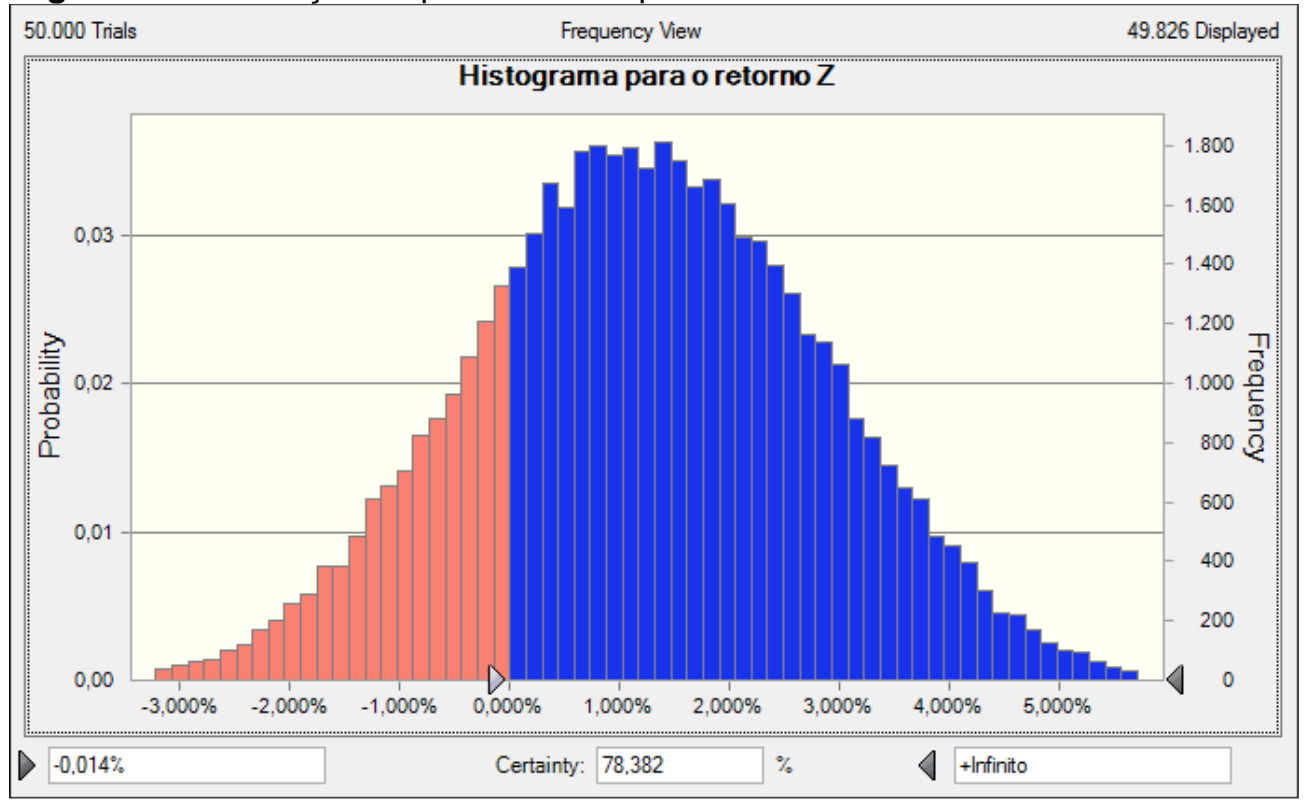

Fonte: Elaborado pelo autor

Com a simulação de cinquenta mil cenários, é possível definir o valor da volatilidade, o, $12,15 \%$.

\subsection{Modelagem por Opções Reais}

O investimento na planta com os requisitos do Inovar-Auto pode ser modelado como uma opção americana de compra. A taxa livre de risco $\left(r_{f}\right)$ adotada é o retorno anual da poupança para o ano de 2014. Os parâmetros da opção podem ser vistos na tabela 7. 
Tabela 7 - Parâmetros da Modelagem da Opção composta

\begin{tabular}{|c|c|c|}
\hline & opção 1 & opção 2 \\
\hline Estágio da árvore $(\mathrm{N})$ : & 3 & \\
\hline expiração $(Y)$ & 1 & 2 \\
\hline volatilidade ( $\left.\sigma^{\prime}\right)$ & $12,15 \%$ & \\
\hline Taxa livre de risco (rf) & $7,10 \%$ & \\
\hline Investimento X & $\mathrm{R} \$ 1.106 .517 .891,50$ & $R \$ 2.872 .541 .002,23$ \\
\hline VPO & $\mathrm{R} \$ 2.026 .660 .251,49$ & \\
\hline Salvage Value & $\mathrm{R} \$ 200.372 .756,63$ & \\
\hline Tamanho do intervalo $(\Delta \mathrm{t}=\mathrm{y} / \mathrm{N})$ & 1 & \\
\hline taxa de crescimento - ativo objeto (u) & 1,129189366 & \\
\hline taxa de crescimento - ativo objeto (d) & 0,885591053 & \\
\hline
\end{tabular}

Fonte: Elaborada pelo autor

\subsubsection{Definição da árvore de eventos}

A árvore de eventos consiste na primeira etapa para a construção da árvore de decisão. Inicialmente, o valor presente do projeto $V P_{0}$ foi introduzido no Step 0. Os demais elementos da primeira linha são calculados multiplicando o elemento anterior por $u$. Cada elemento restante é obtido multiplicando o elemento da coluna anterior e linha anterior por $d$.

A árvore a seguir, figura 4, mostra a evolução dos valores da planta em cada estágio da vida do projeto, iniciando pelo valor presente obtido na avaliação tradicional.

Figura 4 - Árvore de eventos para o investimento no Inovar-Auto.

\begin{tabular}{ccc|c|}
\multicolumn{1}{c}{ Step 0 } & \multicolumn{1}{c}{ Step 2 } & Step 3 \\
\cline { 3 - 4 } & & & $\mathrm{R} \$ 2.917 .973 .130,65$ \\
\cline { 2 - 4 } & & $\mathrm{R} \$ 2.584 .130 .898,42$ & \\
\cline { 2 - 4 } & $\mathrm{R} \$ 2.288 .483 .204,32$ & & $\mathrm{R} \$ 2.288 .483 .204,32$ \\
\hline $\mathrm{R} \$ 2.026 .660 .251,49$ & & $\mathrm{R} \$ 2.026 .660 .251,49$ & \\
\hline \multirow{3}{*}{} & $\mathrm{R} \$ 1.794 .792 .186,89$ & & $\mathrm{R} \$ 2.026 .660 .251,49$ \\
\cline { 2 - 4 } & & $\mathrm{R} \$ 1.794 .792 .186,89$ & \\
\cline { 3 - 4 } & & & $\mathrm{R} \$ 1.794 .792 .186,89$ \\
\hline
\end{tabular}

Fonte: Elaborado pelo autor

\subsubsection{Definição da árvore de decisão}

A partir de uma análise "backward" sobre a árvore de decisões, é possível determinar o valor da opção de investir em cada etapa do projeto da indústria. A 
avaliação tem início na última coluna da árvore. A opção de investimento em uma fase do empreendimento pode ser interpretada como uma opção de compra americana em que o preço de exercício $X$ é equivalente ao valor do investimento a ser feito. Numa opção americana a decisão de pode ser tomada a qualquer momento dentro do período de análise. Assim, para cada célula da última coluna, a opção é avaliada da seguinte maneira:

$$
V_{O R}=\operatorname{Max}[V-X ; 0]
$$

Sendo:

$V_{O R}=$ Valor da opção real;

$\mathrm{V}=$ Valor Presente da árvore de eventos;

$X=$ Preço de exercício da opção.

Ou seja, quando o valor presente do projeto calculado no nó correspondente da árvore de eventos for maior que o valor investido, a opção deve ser exercida e seu valor é $V-X$. Caso contrário, a opção não deve ser exercida e seu valor é zero.

Por exemplo, na primeira célula do Step3:

$V_{O R}=\operatorname{Max}[V-X ; 0]=\operatorname{Max}[2.917 .973,65-2.872 .541 .002,23 ; 0]=R \$ 45.432 .128,42$

A interpretação que se faz é a seguinte: a opção de expandir possui um valor de $R \$ 45.432 .128,42$, ou seja, para este cenário compensa investir na expansão seguindo no sistema Inovar-Auto. Para os demais cenários, o valor da opção é zero e não compensa investir na expansão.

No entanto, é necessário avaliar os demais elementos da árvore. Deste modo, cada Step anterior é avaliado utilizando o método do portfólio replicado para estimar o valor do projeto se ele fosse mantido vivo.

$$
V_{O R}=\operatorname{Max}[V-X ; \text { portfólio }]
$$

O portfólio replicado consiste em $\mathrm{m}$ unidades do ativo replicante, e $B$ unidades do título de dívida sem risco. Então, se o ativo replicante for o valor presente $V$ de um determinado nó da árvore de eventos:

$$
\text { Portfolio }=m V+B
$$

Sejam $C_{u}$ e $C_{d}$ o valor da opção na situação de preços ascendentes e descendentes, respectivamente. Se $V_{u}$ e $V_{d}$ forem respectivamente, o valor do ativo 
objeto na situação de preços ascendentes e descendentes, tem-se o seguinte sistema de equações:

$$
\left\{\begin{array}{l}
m V_{u}+B\left(1+r_{f}\right)=C_{u} \\
m V_{d}+B\left(1+r_{f}\right)=C_{d}
\end{array}\right.
$$

A solução para o sistema de equações é:

$$
\begin{gathered}
m=\frac{C_{u}-C_{d}}{V_{u}-V_{d}} \\
B=\frac{C_{d}-m V_{d}}{\left(1+r_{f}\right)}
\end{gathered}
$$

A decisão do Step 2 ao Step 1 é dado por:

$$
V_{O R}=\operatorname{Máximo}(V-X, \text { portfolio })
$$

Para a primeira célula do step 2, tem-se

$C_{u}=\mathrm{R} \$ 45.432 .128,42$

$C_{d}=R \$ 0,00$

$V_{u}=R \$ 2.917 .973 .130,65$

$V_{d}=R \$ 2.288 .483 .204,32$

Logo, $m=0,072$ e $B=-154.217 .108,9$ e Portfolio=R\$32.287.173,20

Com aplicação da equação 21, o valor máximo é justamente a aplicação no portfolio, ou seja, não é rentável investir na expansão. Para o step 0 , a análise é por opções compostas, ou seja, a expansão (opção americana de compra) ou abandonar o projeto (opção de compra europeia). Deste modo, no Step 0:

$$
V_{O R}=\operatorname{Máximo}(V-X, \text { salvage Value }-V-X, 0)
$$

A figura 5 apresenta a árvore de decisão do projeto. 
Figura 5 - Árvore de decisão do projeto

\begin{tabular}{|c|c|c|c|}
\hline \multirow[t]{4}{*}{ Step 0} & \multirow[t]{3}{*}{ Step 1} & \multirow[t]{2}{*}{ Step 2} & Step 3 \\
\hline & & & Aderir \\
\hline & & Abandonar & \\
\hline & Abandonar & & Não aderir ao Inovar \\
\hline \multirow[t]{4}{*}{ Não Investir } & & Abandonar & \\
\hline & Abandonar & & Não aderir ao Inovar \\
\hline & & Abandonar & \\
\hline & & & Não aderir ao Inovar \\
\hline
\end{tabular}

Fonte: Elaborado pelo autor

Com a montagem da árvore de decisão é possível verificar que o projeto de expansão da empresa, baseados nos requisitos e benefícios do Inovar-Auto não gera valor para a empresa. Deste modo, a empresa não deve gastar com instalação e obras civis, que correspondem a primeira parcela do investimento. É preferível para a empresa deixar o capital a ser investido, rendendo ao mínimo, o custo de capital da empresa, ou seja, $13,25 \%$ ao ano.

\subsection{Análise dos resultados}

Como pode ser verificado na análise tradicional, o investimento apresentou um VPL de $R \$ 37.140 .152,48$, que indica o ganho obtido com a expansão da empresa. No entanto, ao se considerar as incertezas, principalmente nos preços, taxas de juros, quantidade e participação no mercado e definindo-se a variável retorno, dado pela divisão do valor presente do projeto na data um pelo valor presente na data zero, pode-se perceber que existem cenários em que o retorno é negativo. Além disso, é possível definir a volatilidade do retorno do projeto, que é $12.15 \%$.

O investimento inicial de $R \$ 1.106 .517 .891,50$ dá o direito, mas não a obrigação de continuar com o projeto. Ou seja, o investimento inicial é uma opção americana de compra com data de expiração de um ano. A partir do primeiro e segundo ano, são exercidas ou não duas opções de compra europeia. A flexibilidade consiste em abandonar a expansão, quando o valor do projeto for inferior ao salvage value. No step 3, o único cenário favorável é quando o valor presente do projeto é superior ao investimento, ou seja, a situação em que o VPL é positivo. No entanto, para os demais 
cenários da árvore de eventos, o retorno do projeto é inferior ao Salvage Value, estipulado como sendo a receita líquida da empresa sem adotar a política pública Inovar-Auto. Na verdade, o projeto gera retorno acima do Salvage Value quando o preço do automóvel for maior que o definido no Inovar-Auto.

Quando se utiliza o método do portfólio replicante, para analisar a opção composta, fica claro que o retorno do projeto nem se iguala ao retorno em um portfólio livre de risco. Deste modo, a avaliação de projetos, por meio da aplicação da Teoria das Opções mostra que o investimento em uma nova planta não deve ser feito, pois não gera retorno para o investidor. Sendo assim, a opção de abandonar o projeto da planta nos requisitos do Inovar-Auto deve ser aceita e a política pública dentro da atual estrutura de mercado, com taxas de juros elevadas, com o Inovar-Auto de duração até 2017, não é economicamente viável.

\section{CONSIDERAÇÕES}

A política pública Inovar-Auto definida pelo Governo Federal, tem como um dos principais objetivos estimular o desenvolvimento da indústria automobilística dentro do Brasil. Tal política entrou em vigor em dois mil e doze e tem a duração de cinco anos, ou seja, até dois mil e dezessete. Um dos principais benefícios do Inovar-Auto é a redução no IPI e a possibilidade de desenvolver fornecedores através de Projetos de Pesquisa e Desenvolvimento. Os benefícios a serem obtidos pela empresa que adotar a política dependem de alguns requisitos. Para as empresas que decidem se instalar com uma nova planta, a decisão pode ser modelada como um problema de viabilidade empresarial ou análise de investimentos.

No contexto da análise de investimentos, existe a abordagem tradicional, por meio do fluxo de caixa descontado. Neste método, deve-se construir o fluxo de caixa, consistindo de um gasto (que é o investimento: compra ativos imobilizados e instalação), que pode ser em mais de um período e nos demais períodos ou vida do projeto se obtém o fluxo de caixa ou benefícios do projeto. A decisão consiste em determinar qual o ganho com o projeto, por meio do Valor Presente Líquido. Deste modo, o objetivo da análise econômica de projetos é maximizar o ganho e consequentemente o valor da empresa, por meio da escolha de projetos, sujeitos a incertezas econômicas e técnicas. Neste contexto a teoria das opções reais surge 
como uma ferramenta capaz de fornecer a análise de projetos com certo grau de flexibilidade gerencial. A flexibilidade consiste em se verificar a possibilidade de continuar ou abandonar o projeto, diferentemente da análise tradicional.

Esta pesquisa, que consiste na avaliação de adoção de uma política pública, ou seja, a decisão de uma determinada empresa em instalar uma nova planta, nos moldes do Inovar-Auto, foi modelada como uma opção de expansão, viabilizada através de uma opção financeira americana de compra. Deste modo, a empresa pode investir uma parcela nas primeiras obras de instalação da planta, até a data de expiração da opção, cuja data é a data de finalização do projeto, dois mil e dezessete. Tal investimento dá o direito, mas não a obrigação de continuar investindo e terminar a planta ou abandonar, vendendo os ativos, desde que a rentabilidade do projeto seja inferior a receita líquida obtida por meio da venda de automóveis fora dos moldes de inovar. Deste modo, a análise consiste em uma opção composta: uma opção de compra americana e uma opção de venda europeia.

$\mathrm{Na}$ análise tradicional, o VPL apontou que o projeto de construção da planta, aderindo ao Inovar-Auto é viável, ou seja, gera um retorno positivo para a empresa. Quando se modela os componentes do fluxo de caixa como variáveis aleatórias, por meio da Simulação de Monte Carlo, principalmente, as incertezas sobre preços, quantidades e taxas de juros, se obtém a volatilidade do projeto. Tal parâmetro é utilizado para a construção da árvore binomial de decisão e eventos. A análise por opções mostrou que o ganho que o projeto trouxe é inferior ao salvage value (receita liquida com a venda de automóveis, sem adesão ao inovar). Além disso, durante a vida do projeto, o retorno ficou abaixo de uma aplicação em um portfólio composto por um ativo livre de risco. De fato, o investidor é racional, quanto maior o risco maior deve ser o retorno e vice-versa. Deste modo, com a aplicação da Teoria das Opções Reais, concluiu que a adesão ao Inovar-Auto com a construção de uma nova planta não é interessante. Algumas razões para este resultado podem ser obtidas diretamente no mercado automotivo e da própria conjuntura econômica.

A crise econômica que o Brasil está passando, desde dois mil e quinze, fez com que se elevassem a taxa de juros, inviabilizando as formas de captação de recursos através de financiamento. Deste modo, a demanda fica inibida, visto que o carro é adquirido através de financiamento de, no mínimo, vinte e quatro meses. Em dois mil e quatorze a taxa de juros ao mês para o setor automotivo era de $1,2 \%$ ao mês. No 
final de dois mil e quinze a taxa de juros para o setor era de 2,5\% ao mês. Como o Inovar-Auto é previsto até dois mil e dezessete é de se esperar que se mostrasse inviável o projeto de construção de uma planta para atender tal política, pois é um investimento alto para pouco tempo de recuperação, sendo que boa parte deste tempo a demanda está inibida pela alta nos juros. Além disso, a previsão do retorno de novos impostos para a redução do déficit nas contas públicas brasileiras inviabiliza as transações, pois o que se ganha com o IPI reduzido se perde, como por exemplo, em uma movimentação financeira, como por exemplo, a Contribuição Provisória sobre Movimentação Financeira (CPMF).

O impacto dos custos nas receitas da montadora também é significativo, pois no Brasil, os custos chegam a cinquenta por cento do preço unitário do carro enquanto as despesas chegam a vinte e cinco por cento. Deste modo, a Receita operacional fica reduzida, gerando um fluxo de caixa não suficiente para retornar um investimento alto eu um curto espaço de tempo.

\section{REFERÊNCIAS}

ALVES, L. S; WILBERT, M. D. Redução do imposto sobre produto industrializado e a venda de automóveis. In: CONGRESSO USP: INICIAÇÃO CIENTÍFICA EM CONTABILIDADE, 11, 2014. Anais... São Paulo. 2014.

ANAMARI-BEATRICE, S., Real option valuation of public sector R\&D investments with a down-and-out barrier option. Procedia Economics and Finance, v. 15, p. 583-587, 2014.

ANFAVEA. Anuário da Associação Nacional dos Fabricantes de Veículos

Automotores. 2013. Disponível em: <http://www.anfavea.com.br/anuario.html>. Acesso em: 25 maio. 2014.

.Anuário da Associação Nacional dos Fabricantes de Veículos Automotores. 2015. Disponível em: <http://www.anfavea.com.br/anuario.html>. Acesso em: 19 fev. 2015.

Anuário da Associação Nacional dos Fabricantes de Veículos Automotores. 2016. Disponível em: <http://www.anfavea.com.br/anuario.html>. Acesso em: Acesso em: 19 abr. 2016.

Projeta crescimento na produção para 2016. 2016. Disponível em: <http://www.anfavea.com.br/imprensa.html>. Acesso em: 07 jan. 2016.

AZEVEDO, A; PAXSON, D., Developing real option game model. European Journal of Operation Research, v. 237, p. 909-920, 2014.

BARROS, D. C; PEDRO, L. S.As mudanças estruturais do setor automotivo, os impactos da crise e as perspectivas para o Brasil. BNDES Setorial 34. 09/2011. Disponível em <http://www.bndes.gov.br/SiteBNDES.html>. Acesso em: 21 fev. 2015. 
BRANDÃO, M. C., Análise dos parâmetros que influenciam a obtenção do valor da flexibilidade por opções reais no setor elétrico. Dissertação (Mestrado) - Universidade Federal de Itajubá, Itajubá, 2010.

BRASIL, BNDES Setorial 36. Data: 09/2012. Disponível em:

<http://www.bndes.gov.br/SiteBNDES/bndes/bndes_pt/Institucional/Publicacoes/Consulta_E xpressa/Tipo/BNDES_Setorial/201209_01.html. Acesso em: 20 jun. 2014.

BRASIL. Ministério do Desenvolvimento, Indústria e Comércio Exterior - MDIC. Plano Brasil Maior. Disponível em:http://www.brasilmaior.mdic.gov.br/conteudo/128. Acesso em: 20 fev. 2015.

COPELAND, T; ANTIRAKOV, V., Opções reais um novo paradigma para reinventar as avaliações de investimentos. Rio de Janeiro: Campus, 2001.

DAMARAJU, N.L; BARNEY, J.B; MAKHIJA, A.K., Real options in divestment alternatives.Strategic Management Journal, v.36, p. 728-744, 2015.

FABRINI, K. L., Teoria das opções reais: uma abordagem para análise de investimentos em expansão do sistema elétrico. Dissertação (Mestrado) - Universidade Federal de Minas Gerais - UFMG. Belo Horizonte, 2011.

GUTHRIE, G., Regulated prices real options.Telecommunications Policy, v. 36, p.650-663, 2012.

HORN, G;KJÆERLAND, F;MOLNÁR, P;STEEN, B.W.The use of real option theory in Scandinavia's largest companies. International Review of Financial Analysis, v. 41, p.7481, 2015.

LEÃO, C; GOULART, L.O Inovar-Auto e os investimentos em P\&D no setor automotivo. INVENTTA, 2014. Disponível em: <www.inventta.net>. Acesso em: 16 out. 2014.

MARIANI, S.A. Escalada dos automóveis. In: Brasil competitivo: desafios e estratégias para a indústria da transformação. Delloite, 2012.

NORONHA, J. C. N. Investimento em distribuição de energia elétrica sob incerteza regulatória utilizando opções reais. Tese (Doutorado)- Universidade Federal de Itajubá, Itajubá, 2012.

OLIVEIRA, Ualison Rebula; ROCHA, Henrique Martins. Gerenciamento de riscos operacionais em montadoras de veículos. Pretexto. Belo Horizonte. v.15, n.4. p. 27-45. ou./dez., 2014.

SHIBATA, T; NISHIHARA, M., Investment timing, debt structure, and financing constraints. European Journal of operation Research, v. 241, p. 513-526, 2015.

ZEE, D. V; SPINLER, S. Real option valuation of public sector R\&D investments with a down-and-out barrier option.Technovation, v. 34, p. 477-484, 2014.

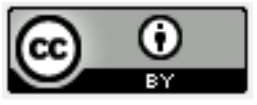

Artigo recebido em 26/09/2016 e aceito para publicação em 05/10/2017 DOI: http://dx.doi.org/10.14488/1676-1901.v18i1.2582 